\title{
Analisis Gangguan Tidak Seimbang pada Line Transmisi GI Sungguminasa-GI Tallasa
}

\author{
Marwan $^{1}$, Ruslan L ${ }^{1}$, Nur Malasari Samsul ${ }^{1, a}$ \\ ${ }^{1}$ Program Studi DIV Teknik Listrik, JurusanTeknik Elektro, Politeknik Negeri Ujung Pandang \\ Jl.Perintis Kemerdekaan km. 10 Makassar 90245 \\ anurmalasarisamsul88@gmail.com
}

\begin{abstract}
The main purpose of this research is to determine the short circuit current when there is a fault occurred on Transmission line between Sungguminasa Sub Station and Tallasa Sub Station. PT. PLN measured that the short circuit current on this transmission line is $2.8 \mathrm{kA}$. To justify the result, symmetrical component method is applied using MATLAB. The results shows that measured value from PLN is equal with the obtained results using MATLAB. This research was conducted on $19^{\text {th }}$ January 2016 at 14:13 WITA.
\end{abstract}

Keywords-Transmission, fault, symmetrical component, and MATLAB.

\begin{abstract}
Abstrak - Tujuan dari penelitian adalah untuk menentukan besar arus hubung singkat ketika terjadi gangguan pada line transmisi antara gardu induk Sungguminasa dan gardu induk Talllasa. Besarnya nilai arus hubung singkat yang diperoleh dari hasil pengukuran yang dilakukan oleh PT. PLN (persero) sebesar 2,8 kA. Untuk menjustifikasi hasil pengukuran tersebut maka digunakan metode komponen simetris untuk menghitung besar arus hubung singkat dengan menggunakan MATLAB. Besarnya nilai yang diperoleh dari data pengukuran PLN sama dengan besarnya nilai yang didapatkan dari hasil perhitungan. Penelitian ini dilakukan saat terjadi gangguan pada tanggal 19 Januari 2016 pukul 14:13 WITA.
\end{abstract}

Kata kunci - Transmisi, gangguan, komponen simetris, MATLAB.

\section{Pendahuluan}

Gangguan yang terjadi pada sistem tenaga listrik sangat beragam besaran dan jenisnya. Gangguan dalam sistem tenaga listrik adalah keadaan tidak normal dimana keadaan ini dapat mengakibatkan terganggunya kontinuitas pelayanan tenaga listrik. Secara umum klasifikasi gangguan pada sistem tenaga listrik disebabkan oleh 2 faktor, yaitu [1,9]:

1. Gangguan yang berasal dari sistem, dan

2. Gangguan yang berasal dari luar sistem.
Penyebab gangguan yang berasal dari dalam sistem antara lain [3] :

1. Tegangan dan arus abnormal,

2. pemasangan yang kurang baik,

3. kesalahan mekanis karena proses penuaan,

4. beban lebih, dan

5. kerusakan material seperti isolator pecah, kawat putus, atau kabel cacat isolasinya.

Sedangkan untuk gangguan yang berasal dari luar sistem antara lain [3]:

1. Gangguan-gangguan mekanis karena pekerjaan galian saluran lain. Gangguan ini terjadi untuk sistem kelistrikan bawah tanah,

2. Pengaruh cuaca seperti hujan, angin, serta petir. Pada gangguan karena petir dapat mengakibatkan gangguan tegangan lebih dan dapat menyebabkan gangguan hubung singkat karena tembus isolasi peralatan (breakdown).

3. Pengaruh lingkungan seperti pohon, binatang dan benda-benda asing serta akibat kecerobohan manusia.

Bila ditinaju dari segi lamanya waktu gangguan, maka dapat dikelompokkan menjadi [3]:

1. Gangguan yang bersifat temporer, yang dapat hilang dengan sendirinya atau dengan memutuskan sesaat bagian yang terganggu dari sumber tegangannya. Gangguan sementara jika tidak dapat hilang dengan segera, baik hilang dengan sendirinya maupun karena bekerjanya alat pengaman dapat berubah menjadi gangguan permanen, dan

2. Gangguan yang bersifat permanen, dimana untuk membebaskannya diperlukan tindakan perbaikan dan/atau menyingkirkan penyebab gangguan tersebut.

Untuk gangguan yang bersifat sementara setelah arus gangguannya terputus misalnya karena terbukanya circuit breaker oleh rele pengamannya, peralatan atau saluran yang terganggu tersebut siap dioperasikan 
kembali. Sedangkan pada gangguan permanen terjadi kerusakan yang bersifat permanen sehingga baru bisa dioperasikan kembali setelah bagian yang rusak diperbaiki atau diganti. Pada saat terjadi gangguan akan mengalir arus yang sangat besar pada fasa yang terganggu menuju titik gangguan, dimana arus gangguan tersebut mempunyai harga yang jauh lebih besar dari rating arus maksimum yang diijinkan, sehingga terjadi kenaikan temperatur yang dapat mengakibatkan kerusakan pada peralatan listrik yang digunakan.

\section{Literatur Review}

\section{A. Gangguan Tidak Seimbang}

Pada saat terjadi gangguan tidak seimbang, magnitude dari tegangan serta arus yang mengalir pada setiap fasa berbeda. Gangguan tidak simetri ini terjadi sebagai akibat gangguan hubung singkat satu fasa ke tanah, gangguan hubung singkat dua fasa, atau gangguan hubung singkat dua fasa ke tanah. Gangguangangguan tidak simetri akan menyebabkan mengalirnya arus tak seimbang dalam sistem sehingga untuk analisa gangguan digunakan metode komponen simetri untuk menentukan arus maupun tegangan di semua bagian sistem setelah terjadi gangguan. Gangguan ini akan mengakibatkan arus lebih pada fasa yang terganggu dan juga akan dapat mengakibatkan kenaikan tegangan pada fasa yang tidak terganggu. Gangguan dapat diperkecil dengan cara pemeliharaannya. Adapun akibat-akibat yang ditimbulkan dengan adanya gangguan hubung singkat tersebut antara lain [1-3,5]:

1. Rusaknya peralatan listrik yang berada dekat dengan gangguan yang disebabkan arus-arus yang besar, arus tak seimbang maupun tegangan-tegangan rendah,

2. Berkurangnya stabilitas daya sistem tersebut, dan

3.Terhentinya kontinuitas pelayanan listrik kepada konsumen apabila gangguan hubung singkat tersebut sampai mengakibatkan bekerjanya $\mathrm{CB}$ yang biasa disebut dengan pemadaman listrik.

\section{B. Gangguan Hubung Singkat Satu fasa ke Tanah}

Untuk gangguan hubung singkat satu fasa ke tanah, fasa a mengalami gangguan. Gangguan dapat digambarkan pada gambar dibawah ini[4]:

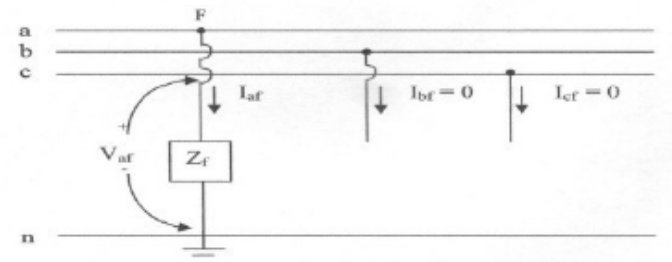

Gambar 1. Gangguan hubung singkat satu fasa ke tanah

Dimana $\mathrm{Ib}=\mathrm{Ic}=0$

$\mathrm{Ia}=\frac{V L-N}{Z G}(\mathrm{kA})$

Keterangan :

$\mathrm{ZG}=\frac{z 1+z 2+z}{3}(\mathrm{ohm})$

Maka arus gangguan 1 fasa ke tanah

$$
\text { If }(\mathrm{Ia})=\frac{3 V L-(\mathbb{E} \mathrm{d})}{Z 1+z 2+Z 0} \quad(\mathrm{kA})
$$

\section{Metode Kompenen Simetris}

Metode komponen simetris digunakan untuk memahami dan menganalisis operasi sistem tenaga listrik pada kondisi tidak seimbang. Berbagai jenis ketidakseimbangan pada sistem tenaga listrik disebabkan oleh gangguan antara phasa dan/atau ke bumi (fasa ke fasa, dua fasa ke tanah dan satu fasa ke tanah), fasa terbuka, impedansi tidak seimbang dan kombinasinya. Dengan menggunakan metode ini sistem tiga fasa tidak seimbang dapat direpresentasikan dengan menggunakan teori komponen simetris yaitu berdasarkan [1-3] :

1. Komponen urutan positif (positive sequence components) yang terdiri dari tiga fasor yang sama besarnya, terpisah satu dengan yang lain dalam fasa sebesar $120^{\circ}$, dan mempunyai urutan fasa yang sama seperti fasor aslinya,

2. Komponen urutan negatif (negatif sequence components) yang terdiri dari tiga fasor yang sama besarnya, terpisah satu dengan yang lain dalam fasa sebesar $120^{\circ}$, dan mempunyai urutan fasa yang berlawanan dengan fasor aslinya, dan

3. Komponen urutan nol terdiri dari tiga fasor yang sama besarnya dan dengan penggeseran fasa nol antara fasor yang satu dengan yang lain.

Telah menjadi kebiasaan umum, ketika memecahkan permasalahan dengan menggunakan komponen simetris bahwa ketiga fasa dari sistem dinyatakan sebagai a, b dan $\mathrm{c}$ dengan cara demikian 
sehingga urutan fasa tegangan dan arus dalam sistem adalah abc. Jadi, urutan fasa komponen urutan positif dari fasor tak seimbang itu adalah abc, sedangkan urutan fasa dari komponen urutan negatif adalah acb. Jika fasor aslinya adalah tegangan, maka tegangan tersebut dapat dinyatakan dengan $\mathrm{Va}, \mathrm{Vb}$, dan $\mathrm{Vc}$. Ketiga himpunan komponen simeris dinyatakan dengan subskrip tambahan 1 untuk komponen urutan urutan positif, 2 untuk komponen urutan negatif, dan 0 untuk komponen urutan 0 . Komponen urutan positif dari $\mathrm{Va}, \mathrm{Vb}$, dan $\mathrm{Vc}$ adalah Va1, Vb1, dan Vc1. Demikian pula, komponen urutan negatif adalah $\mathrm{Va} 2, \mathrm{Vb} 2$, dan $\mathrm{Vc} 2$, sedangkan komponen urutan nol adalah $\mathrm{Va} 0, \mathrm{Vb} 0$, dan $\mathrm{Vc} 0$. Gambar 2 menunjukkan tiga himpunan komponen simetris. Fasor arus akan dinyatakan dengan $I$ dengan subskrip seperti untuk tegangan tersebut [4].

Karena setiap fasor tak seimbang, yang asli adalah jumlah komponen, fasor asli yang dinyatakan dalam suku suku komponennya adalah $[1,4,5]$ :

$$
\begin{aligned}
& \mathrm{Va}=\mathrm{Va} 1+\mathrm{Va} 2+\mathrm{Va} 0 \\
& \mathrm{Vb}=\mathrm{Vb} 1+\mathrm{Vb} 2+\mathrm{Vb} 0 \\
& \mathrm{Vc}=\mathrm{Vc} 1+\mathrm{Vc} 2+\mathrm{Vc} 0
\end{aligned}
$$

Sintesis himpunan tiga fasor tak seimbang dari ketiga himpunan komponen simetris dalam gambar 2 diperlihatkan pada gambar 4
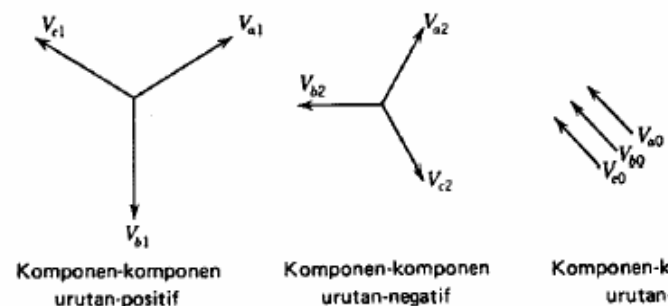

Komponen-komponen urutan-positif urutan-negatif urutan-nol

Gambar 2 Komponen urutan positif, negatif, dan nol (Sumber : Komponen-simetris-dan-impedansi-urutan-uny-acid.html)

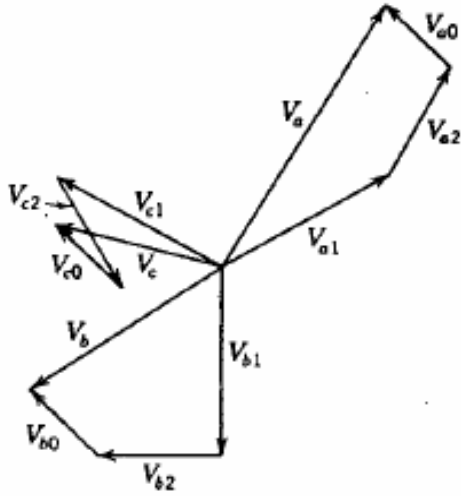

Gambar 3 Penjumlahan secara grafis komponen komponen (Sumber : Komponensimetris-dan-impedansi-urutan-uny-ac-id.html)

Pada Gambar 3, sintesis tiga fasor tak simetris dari tiga himpunan fasor simetris. Sintesis ini telah dilakukan sesuai dengan persamaan yang dituliskan di atas. Mula mula, diperhatikan bahwa banyaknya kuantitas yang diketahui dapat dikurangi dengan menyatakan masing masing komponen $\mathrm{Vb}$ dan $\mathrm{Vc}$ sebagai hasil kali fungsi operator a dan komponen Va. Dengan berpedoman pada gambar 5, hubungan berikut dapat diperiksa kebenarannya [1]:

$$
\begin{array}{rlrl}
\mathrm{V}_{\mathrm{b} 1} & =\mathrm{a}^{2} \mathrm{~V}_{\mathrm{a} 1} & \mathrm{~V}_{\mathrm{c} 1} & =\mathrm{aV}_{\mathrm{a} 1} \\
\mathrm{~V}_{\mathrm{b} 2} & =\mathrm{aV}_{\mathrm{a} 2} & \mathrm{~V}_{\mathrm{c} 2}=\mathrm{a} 2 \mathrm{~V}_{\mathrm{a} 2} \\
\mathrm{~V}_{\mathrm{b} 0}=\mathrm{V}_{\mathrm{a} 0} & \mathrm{~V}_{\mathrm{c} 0}=\mathrm{V}_{\mathrm{a} 0}
\end{array}
$$

Dengan mengulangi persamaan (4) dan memasukkan persamaan (7) ke dalam persamaan (5) dan (6) dihasilkan [1]:

$$
\begin{aligned}
& \mathrm{V}_{\mathrm{a}}=\mathrm{V}_{\mathrm{a} 1}+\mathrm{V}_{\mathrm{a} 2}+\mathrm{V}_{\mathrm{a} 0} \\
& \mathrm{~V}_{\mathrm{b}}=\mathrm{a}^{2} \mathrm{~V}_{\mathrm{a} 1}+\mathrm{aV}_{\mathrm{a} 2}+\mathrm{V}_{\mathrm{a} 0} \\
& \mathrm{~V}_{\mathrm{c}}=\mathrm{a} \mathrm{V}_{\mathrm{a} 1}+\mathrm{a}^{2} \mathrm{~V}_{\mathrm{a} 2}+\mathrm{V}_{\mathrm{a} 0}
\end{aligned}
$$

Dari persamaan 5, 6,dan 7 untuk menentukan tegangan pada setiap fasa digunakan komponen simetris dimana untuk menentukannya dengan persamaan sebagai berikut [1]:

$$
\begin{aligned}
\mathrm{V}_{\mathrm{a}} 1 & =\text { Ea- Ia } 1 \mathrm{z} 1 \\
\mathrm{~V}_{\mathrm{a}} 2 & =-\mathrm{Ia} 2 . \mathrm{z} 2 \\
\mathrm{~V}_{\mathrm{a}} 0 & =-\mathrm{Ia} 0 . \mathrm{z} 0
\end{aligned}
$$


Persamaan yang terdahulu sebenarnya dapat pula ditulis untuk setiap himpunan fasor yang berhubungan, dan kita dapat pula menuliskannya untuk arus sebagai ganti tegangan. Persamaan tersebut dapat diselesaikan baik secara analitis maupun secara grafis. Karena beberapa persamaan terdahulu sangat mendasar, maka kita tulis ringkasan untuk arus[1,4,5]:

$$
\begin{aligned}
& I_{a}=I_{a 1}+I_{a 2}+I_{a 0} \\
& I_{b}=a^{2} I_{a 1}+a_{a}+I_{a 0} \\
& I_{c}=a_{a 1}+a^{2} I_{a 2}+I_{a} 0
\end{aligned}
$$

\section{Metode Penelitian}

Metode yang digunakan dalam penelitian ini adalah dengan menggunakan metode komponen simetris. Dalam penelitian ini besarnya nilai arus hubung singkat yang terukur pada saat terjadi gangguan akan dibandingkan dengan hasil yang diperoleh dari hasil analisis perhitungan. Dalam memudahkan melakukan analisis maka digunakan software MATLAB dalam menghitung besar arus gubung singkat.

Dari persamaan 11 dilihat bahwa untuk menentukan arus gangguan satu fasa ke tanah dapat digunakan urutan komponen simetris dari arus dimana rumus yang digunakan untuk menentukan arus komponen simetris adalah $[1,5,6]$ :

$$
\mathrm{Ia} 1=\mathrm{Ia} 2=\mathrm{Ia} 0 \quad=\frac{E a}{Z 1+Z 2+Z 0}
$$

Cara yang dilakukan dalam menghitung besar arus gangguan hubung singkat pada suatu komponen simetris dalam sistem gangguan adalah mengetahui terlebih dahulu nilai impedansi saluran, kemudian nilai impedansi tersebut diubah kedalam bentuk perunit(pu). Dengan persamaan [1]:

$$
\mathrm{Z}(\mathrm{pu})=\frac{Z \text { a s }}{Z \text { b } a} \int^{i}(\mathrm{pu})
$$

Untuk mengetahui nilai Impedansi basenya (Zbase) dimasukkan rumus [1]:

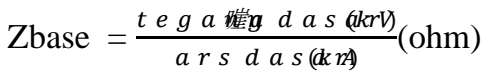

Ket :

$\mathrm{Z}(\mathrm{pu}) \quad=$ Impedansi dalam perunit(pu)

Zasli = Impedansi asli dari komponen(ohm)

$$
\begin{aligned}
& \text { Zbase }=\text { Impedansi dasar(ohm) } \\
& \text { kVbase }=\text { Tegangan dasar(kV) } \\
& \text { kAbase }=\text { Arus dasar(kA) }
\end{aligned}
$$

Nilai dasar sangat berguna untuk mengetahui nilai dari impedansi perunit, karena dalam suatu sistem biasanya memiliki nilai yang berbeda beda. Oleh karena itu, besaran diubah dalam perunit dengan cara membagi dengan nilai base atau nilai dasar untuk memudahkan dalam perhitungan.

Dengan menjumlahkan nilai impedansi gangguan dari masing masing komponen dan dibagikan dengan nilai tegangan sumber sebesar $1 \mathrm{Pu}$ maka didapatkan nilai arus gangguan dalam bentuk per unit. Adapun rumus untuk mendapatkan nilai arus gangguan asli pada masing masing komponen simetris digunakan persamaan [1] :

$\mathrm{Ia} 0=\mathrm{Ia} 1=\mathrm{Ia} 2(\mathrm{asli})=\mathrm{I}(\mathrm{pu}) \mathrm{xIbase}$

Dengan rumus mencari Ibase adalah :

$$
\text { Ibase }=\frac{\text { M V A b a }}{\sqrt{3} X \text { V b a }}(\mathrm{kA})
$$

Ket:

MVAbase $=$ Daya dasar (MVA)

Ibase $\quad=$ Arus dasar $(\mathrm{kA})$

KVbase = Tegangan dasar $(\mathrm{kV})$

Zbase $=$ Impedansi Dasar $(\mathrm{ohm})$

\section{Hasil dan Pembahasan}

\subsection{Kronologi Gangguan}

Pada tanggal 19 Januari 2016 pukul 14:13 WITA terjadi gangguan transmisi pada sistem Sulselbar yang mengakibatkan Black Out (pemadaman meluas), gangguan tersebut terjadi bersamaan dengan hujan dan angin kencang disertai petir, menyebabkan lepasnya beban 200 MW yang menyebabkan sistem Sulselrabar collapse. Dari indikasi yang ada diduga gangguan terjadi di wilayah section $150 \mathrm{KV}$ antara ruas Sungguminasa-Tallasa. Gangguan yang terjadi pada sistem tersebut merupakan salah satu jenis gangguan hubung singkat satu fasa ke tanah yang menyebabkan line Sungguminasa-Tallasa mengalami trip. Line Tallasa di GI Sungguminasa sukses reclose, namun line 
Sungguminasa di GI Tallasa mengalami final trip karena kegagalan teleproteksi mengirim sinyal dari GI Tallasa ke GI Sungguminasa.

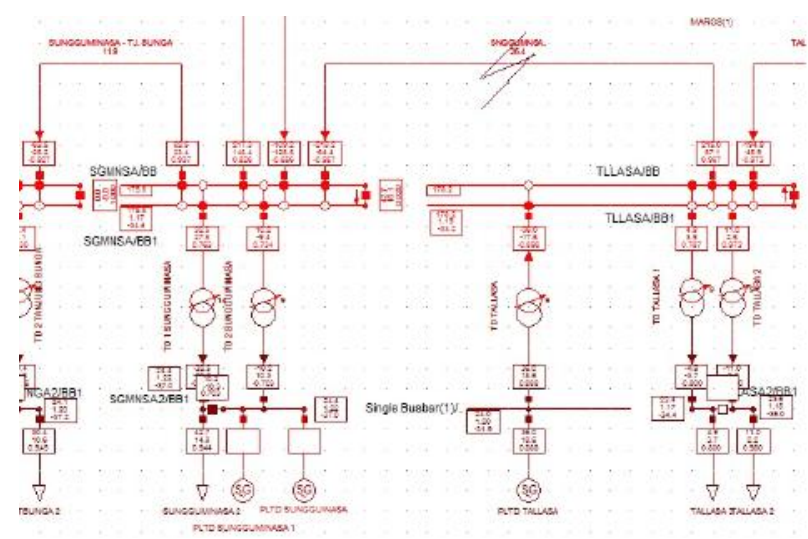

Gambar 4 Single Line Diagram Blackout

\subsection{Menentukan Nilai Arus Hubung Singkat (Ia)}

\subsubsection{Hasil Pengukuran dan evaluasi PT.PLN (Persero)}

Dalam melakukan pengukuran besar arus hubung singkat yang terjadi jika terjadi gangguan, maka pihak PT. PLN (persero) menggunakan data pengukuran arus dan tegangan seperti yang dijelaskan melalui gambar berikut ini:

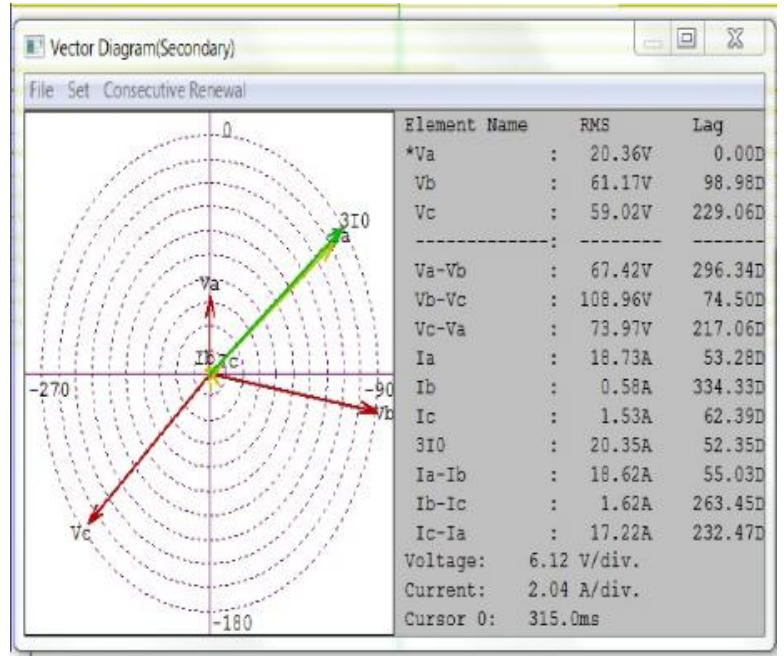

Gambar 5 Data arus dan tegangan saat gangguan

Bisa dilihat pada gambar 5 data arus dan gangguan, nilai arus pada saat gangguan yang terjadi pada fasa a adalah $18.73 \mathrm{~A}$, dimana nilai ini adalah hasil dari nilai secondary (sekunder). Untuk menentukan arus gangguan yang sebenarnya(nilai arus primer) digunakan ratio current transformator sebesar 800/5A sebagai perbandingan, seperti yang dijelaskan dibawah ini :

$$
\begin{aligned}
& \text { ArusPrime erdprim)er } \\
& \overline{\text { A r us S e ku }}=\overline{\overline{\text { ddesre } k u n \not l} \text { er }} \\
& \frac{80}{5}{ }^{0}=\frac{I a}{187} \\
& \frac{80 \oplus 187}{5}=2.880 \mathrm{~A}(2,8 \mathrm{kA})
\end{aligned}
$$

Sehingga besar arus hubung singkat adalah: $2.880 \mathrm{~A}$ atau sebesar $2,8 \mathrm{kA}$.

4.2.2 Hasil perhitungan dengan metode Komponen Simetris

Setelah impedansi saluran telah diubah kedalam bentuk per unit, maka selanjutnya menyelesaikan arus komponen simetris :

$$
\begin{aligned}
\mathrm{Ia}_{0}: \mathrm{Ia}_{1}: \mathrm{Ia}_{2} & =\frac{E a}{Z \text { ot } Z 1+Z 2} \\
& =\frac{1}{(0,052+j 0,256)+2(0,0104+j 0,069)} \\
& =\frac{1}{(0,052+j 0,256)+(0,0208+j 0,138)} \\
& =\frac{1}{0,0728+j 0,394} \\
& =0,453-\mathrm{j} 2,45\left(2,49 \angle-79,53^{\circ}\right.
\end{aligned}
$$

(pu) )

$$
\begin{aligned}
& \mathrm{Ia}_{0}(\mathrm{asli}) \quad=\quad \mathrm{Ia}_{0}(\mathrm{pu}) \cdot \mathrm{Ia}_{0}(\text { base }) \\
& \left.\mathrm{Ia}_{0}(\text { base })=\quad \frac{M V A b a}{\sqrt{3} . k V b a}{ }_{S}^{\rho} \mathrm{K}^{e} \mathrm{~A}\right) \\
& =\frac{100}{\sqrt{3.150}} \\
& =\quad \frac{100}{25,807} \\
& =\quad 0,3849(\mathrm{kA}) \\
& \mathrm{Ia}_{0}(\text { asli }) \quad=\quad \mathrm{I}(\mathrm{pu}) \cdot \mathrm{I}(\text { base }) \\
& =\quad 2,49 \angle-79,53^{\circ}(\mathrm{pu}) \cdot 0,3849 \\
& =\quad 0,174-\mathrm{j} 0,94(0,958 \angle-
\end{aligned}
$$

$79,5^{\circ} \mathrm{kA}$

Ia

$$
\begin{array}{ll}
= & 3 \cdot \mathrm{Ia}_{0}\left(\mathrm{Ia}_{1}+\mathrm{Ia}_{2}+\mathrm{Ia}_{0}\right) \\
= & 3 \cdot 0,958 \angle-79,5^{\circ} \mathrm{kA} \\
= & 2,87 \angle-79,5^{\circ} \mathrm{kA}
\end{array}
$$


Arus hubung singkat yang dihasilkan dengan cara perhitungan manual menggunakan metode komponen simetris ialah $2,87 \angle-79,5^{\circ} \mathrm{kA}$.

Hasil tersebut diatas dapat dijustifikasi dengan menggunakan MATLAB:

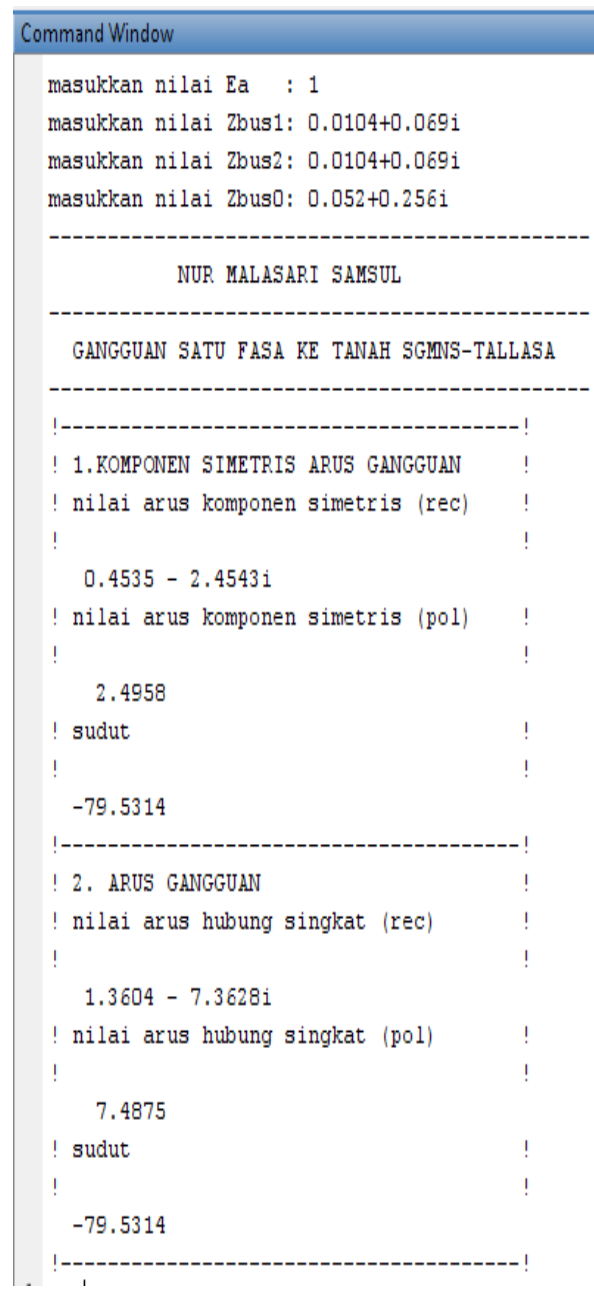

Gambar 6 Tampilan MATLAB setelah dijalankan

Berdasarkan hasil diatas, diperoleh nilai arus komponen simetris sebesar 2,49 (pu), dan akan dikonversi ke (kA) berdasarkan data yang didapatkan. Hasil konversi ke (kA) adalah sebagai berikut:

$$
\begin{aligned}
& \mathrm{Ia}_{0}(\text { asli }) \quad=\quad \mathrm{I}(\mathrm{pu}) . \mathrm{I} \text { (base) } \\
& \mathrm{Ia}_{0} \text { (base ) } \quad=\quad \frac{M V A b a}{\sqrt{3} \cdot k V b a}\left(\mathrm{k}_{e}^{e} \mathrm{~A}\right) \\
& =\frac{100}{\sqrt{3.150}}
\end{aligned}
$$

$$
\begin{aligned}
= & \frac{100}{25,807} \\
= & 0,3849(\mathrm{kA}) \\
= & \mathrm{I}(\mathrm{pu}) \cdot \mathrm{I}(\text { base }) \\
= & 2,49 \angle-79,5^{\circ}(\mathrm{pu}) \cdot 0,3849 \\
= & 0,958 \angle-79 \cdot 5^{\circ} \mathrm{kA} \\
\mathrm{Ia} & =3 \cdot \mathrm{Ia}_{0}\left(\mathrm{Ia}_{1}+\mathrm{Ia}_{2}+\mathrm{Ia}_{0}\right) \\
& =3 \cdot 0,958 \angle-79 \cdot 5^{\circ} \mathrm{kA} \\
& =2,87 \angle-79.5^{\circ} \mathrm{kA}
\end{aligned}
$$

Sama halnya jika arus gangguan hasil dari MATLAB dikonversi ke kA :

$$
\begin{aligned}
& \mathrm{Ia}(\operatorname{asli})=\mathrm{I}(\mathrm{pu}) \cdot \mathrm{I}(\text { base }) \\
& \text { Ia (base) }=\quad \frac{M V A b a}{\sqrt{3} \cdot k V b a}\left(\mathrm{k}_{e}^{e} \mathrm{~A}\right) \\
& =\frac{100}{\sqrt{3.150}} \\
& =\frac{100}{25,807} \\
& =\quad 0,3849(\mathrm{kA}) \\
& \mathrm{Ia}(\text { asli })=\quad \mathrm{I}(\mathrm{pu}) . \mathrm{I}(\text { base }) \\
& =\quad 7,4 \angle-79^{\circ}(\mathrm{pu}) \cdot 0,3849(\mathrm{kA}) \\
& =\quad 2,87 \angle-79.5^{\circ} \mathrm{kA}
\end{aligned}
$$

Hasil penentuan arus hubung singkat yang diperoleh adalah $2,87 \angle-79,5^{\circ} \mathrm{kA}$.

\section{Kesimpulan}

Besarnya arus gangguan yang terjadi pada Line transsmisi antara Gardu Induk Sungguminasa dan gardu induk Tallasa yang terjadi pada tangal 19 Januari 2016 adalah sebesar 2,8 kA. Besarnya nilai arus gangguan tersebut diperoleh dari hasil pengukuran yang dilakukan oleh PT. PLN (Persero). Hasil pengukuran tersebut sama dengan hasil perhitungan yang didapatkan dengan menggunakan metode komponen simetris. 


\section{Daftar Pustaka}

[1] Marsudi, Djiteng. (2006). "Operasi Sistem Tenaga Listrik”. Yogyakarta: Graha Ilmu.

[2] Rahim,Aulia (2011) "Studi Hubung Singkat Tidak Seimbang": Universitas Andalas

[3] Stevenson, W.D, Jr (1994). "Analisis Sistem Tenaga Listrik”, diterjemahkan oleh Idris, Kemal Ir. Edisi Keempat.Bandung:Penerbit Erlangga.

[4] Cekdin, Cekmas. (2010). "Sistem Tenaga Listrik Contoh Soal dan Penyelesaian Menggunakan MATLAB”. Yogyakarta: ANDI.

[5] Supardi, Agus. (2014) "Analisis gangguan hubung singkat satu fasa ke tanah".Surakarta

[6] Dasman. (2016). Studi Gangguan Hubung Singkat Satu Fasa Ke Tanah:Jurnal Elektro.Instititut Tekonologi Padang.

[7] Sentoso.Julius(2015). Analisis gangguan satu fasa ke tanah:Jurnal Elektro.Universitas Kristen Petra

[8] Bawan,Ek (2013) Estimasi Pembebanan Trafo GI 150kV.Jurnal:Ilmiah Forensik.Universitas Negeri Papua

[9] Hutauruk,Ir,Msc. (1985). "Transmisi Daya Listrik". Jakarta:Erlangga

[10] PLN, (2015). "Data saluran transmisi Sulselrabar”Makassar:PT PLN(Persero) Sulselrabar.

[11] Jubilater Simanjuntak, 2009. Studi Gangguan Hubung Singkat Satu Fasa ke Tanah Akibat Sambaran Petir Pada Saluran Transmisi. Medan: Jurnal TA Universitas Sumatera Utara.

[12] Asep Parli. Identifikasi Jenis dan Lokasi Gangguan Hubung Singkat Pada Saluran Transmisi. Jurnal TA Universitas Bengkulu. 